\title{
TABLE ERRATA
}

329.-C. C. Brunns, A New Manual of Logarithms to Seven Places of Decimals,

Eighteenth stereotype edition, D. Van Nostrand Co., Inc., New York, 1941.

The following typographical error exists on page 13: in the mantissa of the logarithm of 13817 the missing fourth decimal digit should be 4 .

Fletcher, Miller, Rosenhead \& Comrie, An Index of Mathematical Tables, Second edition, 1962, vol. II, p. 798, states that this edition of the Bruhns tables has not been completely checked.

Instituto Technologico de Chihuahua

Charles R. Sexton

Chihauhua, Mexico

Editorial Note: For a detailed discussion of the numerous editions of this work see MTAC, v. 2, 1946-1947, p. 338-339. The preceding error appears to occur in only the edition cited.

330.-W. E. Milne, Numerical Calculus, Princeton University Press, Princeton, 1949.

On page 260, the third term of the expression given for the Legendre polynomial $P_{5}(x)$, adapted to the interval $0 \leqq x \leqq 1$, should read $210 x^{2}$.

On page 374 , in Table V, which presents decimal values of such polynomials, the value of $P_{3}(.35)$ should read -.38250 , instead of -.39250 .

Charles R. Sexton

331.-G. W. Spenceley \& R. M. Spenceley, Smithsonian Elliptic Functions Tables, The Smithsonian Institution, Washington, D.C., 1947. [See also MTE 318, Math. Comp., v. 16, 1962, p. 511-512.]

$\begin{array}{ccccc}\text { page } & \text { quantity } & \text { for } & \text { read } \\ 3 & A\left(23^{\circ}, 1^{\circ}\right) & 0.390731127936 & 0.390731128009 \\ 6 & d n\left(39^{\circ}, 2^{\circ}\right) & 0.999758696196 & 0.999758696206 \\ 8 & d n\left(51^{\circ}, 2^{\circ}\right) & 0.999632042034 & 0.999632042024 \\ 11 & \phi\left(37^{\circ}, 3^{\circ}\right) & 0.646101383557 & 0.646101408606 \\ & \phi\left(41^{\circ}, 3^{\circ}\right) & 0.715924516074 & 0.715924516084 \\ 19 & \phi\left(21^{\circ}, 5^{\circ}\right) & 0.367157143846 & 0.367157143742 \\ 21 & \phi\left(60^{\circ}, 5^{\circ}\right) & 1.047974316260 & 1.048022797628 \\ & & & & \\ & & & & \text { WERNER E. KNOLLE } \\ & & & & \text { WILLIAM A. ALLEN }\end{array}$

Land-Air, Inc.

Point Mugu, California, and

Test Data Division

Pacific Missile Range

Point Mugu, California 
332.-G. W. Spenceley, R. M. Spenceley, \& E. R. Epperson, Smithsonian Logarithmic Tables to Base e and Base 10, The Smithsonian Institution, Washington, D.C., 1952.

On page 383 , the mantissa of $\log 9005$ should read $95448 \ldots$ instead of $85448 \ldots$.

This information supplements errata previously reported. See especially Math. Comp., v. 17, p. 103, where other references are cited.

Charles R. Sexton

\section{CORRIGENDA}

John Brillhart, "Concerning the numbers $2^{2 p}+1, p$ prime," Math. Comp., v. 16,1962 , p. $424-430$.

On page 428 , delete the entry " $c$ " in the first column corresponding to $p=769$. No information is available at present regarding the factorability of this number.

University of San Francisco

JohN BrILlHaRT

San Francisco, California

John Brillhart \& G. D. Johnson, "On the factors of certain Mersenne numbers," Math. Comp., v. 14, 1960, p. 365-369.

Corresponding to the second interval, namely $103 \leqq p \leqq 157$, listed in section 2 on page 365 , for $p \neq 151$, read $p \neq 113$ and 151 .

JohN BRILlhart

L. CARlitz, "The coefficients of the leminiscate function," Math. Comp., v. 16, 1962, p. $475-478$.

At the bottom of page 475 , in the expansion of $p(u)$, the second factor in the denominator of the general term should read $(4 n-2)$ ! instead of $4 n-2$.

J.W.W. 